\title{
Journalism capstone units based on agreed principles and standards
}

\begin{abstract}
The concept of capstone units is gaining currency within the Australian Higher Education system, with a growing focus on enhancing graduate employability and assuring graduate outcomes. The aim of this paper is to report on an 18-month study of undergraduate journalism capstone units in Australian universities. Just over half of the universities in Australia that teach journalism (16 out of 30), embed capstone units in their programmes, and the study, which began in September 2015, is part of an Australian Learning and Teaching Fellowship. It is divided into three stages. The first stage involved face-to-face interviews with journalism academics at 16 universities in five States, to discover what type of capstone unit they use, the principles they employ and the skills students need to demonstrate and apply. This data then underwent a validation process. Stage three of the study will develop resources to support journalism educators in the design or redesign of capstone units, especially in the area of agreed principles, standards and best practice.
\end{abstract}

Keywords: Australia, Australian Learning and Teaching, capstone units, curriculum development, employability, graduate capabilities, journalism education

\section{TREVOR CULLEN \\ Edith Cowan University, Perth}

\section{Journalism capstone units in Australia}

RECENT development in Australian journalism education has been the
use of undergraduate journalism capstone units at 16 universities. Uni-
versities increasingly offer capstone subjects as part of their curricula to prepare final-year undergraduates for employment and bridge the gap between academic learning and professional work. However, the current journalism capstone units vary in content, delivery and learning outcomes. Some opt for research projects while others offer professional placements or a selection from a list of core units. Hence, it is difficult to define exactly what constitutes a journalism capstone unit from what is currently on offer. 
For example, at Swinburne University in 2015, the final-year journalism capstone unit was divided into two sections: Capstone A - JOU 30002 and Capstone B - JOU 30003. The description of learning outcomes for Capstone A, which involved a journalism project and reflective essay, stated that the students would gain experience, complete a journalism project and reflect on ethical and legal issues connected with the practice of journalism. The description of learning outcomes for Capstone B was similar, and the learning outcomes included the ability to identify audiences, gain experience in building audiences, become part of an internet-based platform and be able to reflect on journalism practice and the ethical, legal and practical problems encountered. There was an absence of phrases like 'apply' 'measure' or 'demonstrate' capabilities. 'Should' is preferred to 'can'.

It was a similar story at Monash University in 2015. The final-year journalism capstone unit was in fact a professional industry unit where entry depended on negotiation with the unit coordinator. Learning outcomes were expressed with phases like 'students should be able to'. The journalism capstone unit at the University of Canberra in 2015 was also a professional industry placement, but it was one of the few universities in the study that stated in the learning outcomes that students 'will be able to demonstrate ability'. This unit offered concrete learning outcomes while the more optimistic modal verb 'should' created an impression that it is more aspirational than actual.

While these journalism capstones vary in their preference for either a research project or a professional industry placement, there is still the basic issue of how to measure graduate capabilities. As stated before, a professional industry placement is problematic as there is the presumption graduates have actually acquired a certain level of capability. They could form part of a journalism capstone unit, but only as one of a number of other measurement activities. An initial list of core skills to be demonstrated in a journalism capstone unit (judging from existing journalism capstones) includes: research, writing, grammar, digital and social media, video, communication and team skills. Yet, there is inconsistency regarding the inclusion, importance and assessment of these skills.

There should be a way to identify minimum standards and test capabilities to be met by a graduate from a bachelor level degree or enrolled in a major in the field of journalism. This was partially attempted in 2011 with an Office of Learning and Teaching (OLT) Grant entitled: Discipline Network: Journalism, Media and Communication. One aim was to develop systemic discipline standards for undergraduate and postgraduate courses in Australia which encompassed Journalism, Public Relations, Media and Communication Studies and thereby provide some form of benchmarking across the universities in Australia. While this was an important aim, the outcome was difficult to achieve because of the immense variety of views from educators across the three disciplines. Additionally, there 
were no disciplinary guidelines by which to measure standards. Teaching Learning Outcomes (TLOs) provide a guide but do not define the content, teaching and learning approaches used to achieve outcomes.

The lack of agreement on agreed discipline standards was also evident from a 2014 OLT Innovation and Development Grant report which included findings from interviews with 50 tertiary journalism educators and 50 news editors across Australia. There was broad agreement among the educators that journalism education should aim to achieve three key outcomes - build a broad knowledge base, develop research and analytical skills, and teach core media and communication skills. However, in terms of the last outcome, there was a common view that a Professional Industry Placement (PIP), which is commonly used by journalism educators in Australia to test graduate skills and capabilities, was problematic as they were decreasing in number, and students enrolled in them did not necessarily have the required skills and often ended up performing menial tasks in the newsroom (Tanner, Green, Cullen, \& O’Donnell, 2014).

Interviews with the news editors revealed that most of them perceived graduate students enrolled in professional placements as being generally competent with digital media, but often lacking in basic general knowledge and essential newswriting and grammar skills (Tanner, et al., 2014). In fact, professional placements often exposed a graduate's lack of ability rather than improving it. Besides, editors and journalists are often far too busy to instruct, monitor or assess their work practice skills. Industry placements are useful, but they do not provide an adequate measurement of graduate capabilities. Billett (2011) in his investigation into Curriculum and pedagogic bases for effectively integrating practice-based experiences, stresses the need to be clear about what needs to be learnt and to consider options other than supervised placements to secure intended educational purposes.

Finally, St Clair (2015) points to a current challenge - the ever-changing world of journalism that requires journalism students to acquire and demonstrate new capabilities such as enterprising and entrepreneurial skills.

The world of journalism in the digital age is changing faster than university curricula can keep up. News is now produced in forms and on platforms that were non-existent 10 years ago. Journalists may increasingly generate their own work opportunities in entrepreneurial news outlets and start-ups, rather than as employees in legacy newsprint and broadcast media. Substantial workforce contraction has also occurred since 2012 as revenue in print and other traditional media has found new homes in social media and search engines, and over 1000 journalists (or 15 percent of the journalism workforce) were made redundant. Journalism graduates therefore need to be flexible, innovative and enterprising to survive professionally in this evolving setting. (St Clair, 2015) 


\section{Table 1: AQF level 7 criteria}

\section{Summary:}

Graduates at this level will have broad and coherent knowledge and skills for professional work and/or further learning.

\section{Knowledge:}

Graduates at this level will have broad and coherent theoretical and technical knowledge with depth in one or more disciplines or areas of practice.

Skills:

Graduates at this level will have well-developed cognitive, technical and communication skills to select and apply methods and technologies to:

- analyse and evaluate information to complete a range of activites

- analyse, generate and transmit solutions to unpredictable and sometimes complex problems

- transmit knowledge, ideas and skills to others

\section{Application of skills and knowledge:}

Graduates at this level will apply knowledge to demonstrate autonomy, well-developed judgment and responsibility: in contexts that require self-directed work and learning within broad parameters to provide specialist advice and functions

\section{The Australian Qualification Framework (AQF)}

The concept of a capstone unit is gaining currency within the Australian Higher Education system. A major motivating factor is the government's focus on enhancing graduate employability, assuring graduate outcomes and the need to develop capabilities for assuring Higher Education standards. This has led to a debate about academic standards within the Australian Higher Education sector. This critical nexus requires all university degrees and course majors to rigorously map learning outcomes against agreed national standards. In particular, there is a need to map and demonstrate the relationships between generic attributes and disciplinary capabilities; the relationship between skills and knowledge and their application; the relationships between disciplinary communities, professional bodies and industry; and the relationship between macro course structure and micro subject design.

The Australian Qualifications Network (AQF) has published statements of what skills, knowledge and application graduates in Australian universities should achieve when they complete a level 7 qualification — a Bachelor's degree (Table 1). The Qualification Standards are a set of requirements, in the form of a legislative instrument, which are binding on Higher Education providers.

Furthermore, the Tertiary Education Quality Standards Agency (TEQSA) will apply the Threshold Standards, including the Qualification Standards, when deciding whether to grant registration or renew a provider's registration, or to accredit courses. It seems sensible, therefore, to ensure capstone journalism 
units be framed within the context of the level 7 statement and that a capstone unit adheres to the standards outlined in the AQF at level 7.

\section{Methodology}

In Australia 30 universities teach journalism and just over a half of them use at least one journalism capstone unit in their undergraduate programmes. I interviewed journalism educators at the 16 universities that already use journalism capstone units in order to discover what they understood by the term 'capstone', the type of capstone they used and what skills the students had to demonstrate and apply.

A total of 30 face-to-face semi-structured interviews were conducted in the offices of journalism educators in 16 universities in five States. The educators were either heads of journalism or course coordinators. The universities were selected because they offer journalism capstone units (often in diverse formats). The four interview questions were open-ended to allow each participant to describe, as fully or as briefly, the particular reasons for their decisions. Every participant signed an information and consent form before each interview which lasted at least one hour. All the interviews were recorded and later transcribed.

The universities included Monash, Melbourne, RMIT, Swinburne, Canberra, Sydney, South Australia, Wollongong, UTS, Adelaide, Curtin, Murdoch, Notre Dame, Edith Cowan, Deakin and La Trobe. Several follow-up telephone calls were made to obtain both clarifications and further information. The interviews were conducted between September 2015 and June 2016 as stage one of a threestage study. One key aim of the three-stage study was to identify and agree on common principles and standards, and to assist the other 14 tertiary journalism programmes in Australia that want to introduce journalism capstones into their courses (even though some had units that could be easily identified as capstone units).

The interview questions included four questions:

- What do you understand by the term 'capstone unit'?

- What type of capstone units do you use?

- What were the underlying principles for the capstone units?

- What disciplinary and professional skills do students need to demonstrate? I also organised a one-day workshop (in February 2016) on journalism capstone units with journalism educators at four universities in Perth, Western Australia. These included Edith Cowan, Murdoch, Curtin and Notre Dame universities. The participants were asked the same four questions as above, but the session was conducted as an open forum rather than directing questions at individual institutions. None of these universities used the term 'capstone' in their journalism courses. 


\section{Findings from face-to-face interviews}

\section{Question 1. What do you understand by the term 'capstone unit'?}

Generally, the educators agreed that a prime aim of the capstone unit was to improve the employability of the student. This was often achieved through the use of a portfolio that showed various skills that ranged from written, audio, visual, photographic, online and social media skills. Another widely supported view was that a capstone unit should be a final-year unit and it should enable students to demonstrate the skills they had acquired over a three-year journalism degree course. Common phrases used to describe a capstone unit included: 'bringing together of skills and knowledge acquired over a three-year period', 'a full stop on their course', 'a throwback to the future', 'rounding off their degree' and 'making sure they are job ready'.

These descriptions and understandings resonate with the views of other researchers in the field of capstone research such as McNamara et al (2012) who highlighted the aspect of looking back and also forward.

An opportunity for final year students to both look back on their undergraduate study in an effort to make sense of what they have accomplished, and to look forward to a professional existence where they can build on that foundation. It is during the capstone experience that students complete the transition from their primarily student identity to embrace the beginning of their professional identity. (McNamara, et al., 2012)

\section{Question 2. What type of capstone units do you use?}

As part of the recent focus on quality assurance of undergraduate qualifications in Australia, the use of capstone units has increasingly taken a central role in thinking about evidence of programme quality. As a result, many Australian universities have introduced capstones with the twin aims of providing students with an enhanced undergraduate experience and a locus for quality assessment. Capstones come in many different forms, with a wide range of lengths, weightings and activities.

Lee (2015) identifies six common capstone models used across disciplines:

- Externally oriented projects

- Academic inquiry projects

- Practice-oriented simulations

- Practice-based consultancies

- Task oriented simulation

- Professional placements

Findings from interviews with journalism educators at 16 universities revealed that there were three types of third-year capstone units in use: a newsroom 
simulation unit, a project, and an internship (which was commonly used to describe a professional industry placement). The educators used at least one and often two (and sometimes three) types of capstone units. The internship was the most popular, followed by newsroom simulation and then a project.

First, the internship usually consisted of a four-week, full-time internship at a media organisation. This involved consultation with the journalism coordinator about the suitability of the placement. It was a common practice to select high performing students rather than those who were average or struggling with the course. However, several educators argued against using the internship as the only capstone unit as there was often little supervision and mentoring in the newsroom. Frequent discussions with students before, during and after the internship usually provided the most productive outcomes and experience.

The newsroom simulation unit was a popular capstone unit used by the educators as it helped students demonstrate what they had learnt during their three-year undergraduate course. Part of this included a portfolio of published work and achievements.

The third type of journalism capstone involved a project, where the students covered an event or a local social or political issue. Students were exposed to a wide range of journalistic skills from interviewing, writing, editing and keeping production deadlines. Critical reflection was considered a key part of the project.

Generally, the educators were satisfied that the benefits of a capstone unit far outweighed the negatives. For example, several of them said the capstone units enabled students to produce portfolios of their work or showreels. This is now a basic requirement when students apply for jobs at media organisations. Others spoke of how their students, especially in the internship and simulation capstones units (where students adopt newsroom roles and duties), had started to think and act like journalists and how they developed a confident and professional approach to their work. They could also identify gaps in their learning.

On the negative side, there was divided opinion about whether to rely solely on one capstone unit and the university timetable often lacked the flexibility to cater for an intensive vocational course. Only RMIT was able to structure its newsroom simulation unit into a whole day, once a week. Weak students struggled with internships as industry was keen on employing highly motivated, intelligent and determined students.

\section{Question 3. What were the underlying principles for the capstone units?}

Principles provide a guide to the nature and unique importance of the capstone experience in the student journey to graduation and beyond.

In short, the educators stressed a list of five different principles for an effective journalism capstone experience:

- Transition to work and professional practice 
- Integration and extension of prior learning

- Authentic and contextualised experiences

- Student ownership and independence

- Continued development of critical inquiry and creativity

These principles show close similarities to the list of general principles that Lee (2015) found in her research on capstone curriculum. She argues that general principles that cater for diverse courses suit a wide variety of disciplinary capstone units. However, it must be noted that some educators were not in full agreement with these five principles and said they wanted further debate and discussion in order to arrive at an agreed list.

\section{Question 4. What disciplinary and professional skills do students need to demonstrate?}

In brief the skills required by journalism students to successfully pass the capstone unit were divided into two sections-disciplinary (skills) and professional (attitude and behaviour).

\section{Disciplinary skills:}

News writing, audio, online, TV, photographic, video, editing, verification and digital technical skills. Students had to be team player with an extensive social media brand and presence, together with research and analytical skills, and an ability to publish across several mobile platforms. They must be able to generate story ideas and communicate accurately, vividly and memorably. Several educators added that the ability to generate and pitch ideas to editors was essential as well as highly competent interview skills.

\section{Professional skills.}

Several interviewees spoke about the need for ethical practitioners with a solid knowledge of media law and for journalism students to seek truth, accuracy, balance and fairness in news reporting. Also, there was a call for reflective and mindful practitioners who can see the consequences of their professional work.

It is interesting to note that these two lists - disciplinary and professional skills - closely correspond to what the academics and news editors recommended in the 2014 OLT Innovation and Development report (Tanner, et al., 2014). They stated that journalism students should be able, at the end of their course, to demonstrate research, writing, grammar, digital and social media, video, communication and team skills. The two lists provide what needs to be demonstrated but there was division regarding how many skills the students had to demonstrate and which ones were absolutely essential.

Entrepreneurial was a term frequently repeated by the interviewees as the 
world of journalism in the digital age is changing so fast. The result is that journalists find they have to generate work opportunities in entrepreneurial news outlets and start-ups, rather than as employees in mainstream news and broadcast media. Several interviewees argued that their students needed to be far more flexible, innovative and enterprising if they were to survive.

\section{The validation process}

Responses to the four questions in face-to-face interviews with more than 30 journalism academics at 16 Australian universities provided invaluable data on journalism capstone units. There are 30 universities that teach journalism so just over half were involved in the data collection and discussions. These 16 universities were chosen either because they teach capstone units or similar subjects without using the term capstone. The next stage was to achieve agreed statements on the aims of capstone units, a list of skills to demonstrate and apply and what models to use. To avoid extending the research process via more data collection and discussions, the author selected journalism academics from five universities in Melbourne who were representative of the diverse range of the journalism academics in Australia, especially in terms of age and the time spent working as journalists or teachers or both. This group met on August 27 at the Victoria State Library to discuss the second stage of the study - the validation process.

The purpose of the meeting was to:

- present the findings from the data collection on journalism capstone units collected by the author as part of his Australian Learning and Teaching Fellowship

- discuss and identify - in the context of the AQF level 7 statement, the skills and knowledge required by students to successfully complete a capstone unit.

- examine various models of capstone units and identify possible model(s) appropriate to journalism courses in Australian universities.

\section{Aims of a capstone unit}

There was an extended discussion as to what was and should be the nature of a capstone unit. At issue was whether the capstone unit should be primarily a means of learning new knowledge and skills or, while still being a learning experience, be primarily aimed at allowing students to apply their mastery and synthesis of the knowledge and skills gained over the course of their degree or major in journalism.

There was general agreement that a journalism capstone unit should:

- result in a publishable outcome

- provide an opportunity to demonstrate core journalism skills 
- be student-centred and require students to articulate what they wanted to achieve and how they proposed to achieve their aim.

\section{Principles}

After a lively and passionate debate, the validation group agreed on a set of six principles, with the understanding that principles provide a guide to the nature and unique importance of the capstone experience in the student journey to graduation and beyond. While these principles were seen as complementing the five principles mentioned by the 30 journalism academics in face-to-face interviews, it was agreed that the new list provides clearer content and direction.

Transition: Assist students to develop a sense of professional identity and support them to manage their career planning and development.

Integration and closure: Enable students to attain a sense of completion and an understanding of what it means to be a graduate and globally responsible citizen.

Diversity: Enhance students' capacity to engage with diversity in professional contexts.

Engagement: Require students to assume active roles and to apply their learning in realistic, authentic and unfamiliar contexts and to take responsibility for their own work.

Assessment: Align assessment practice with the agreed capstone principles. Ask students to reflect on their own capabilities and performance.

Evaluation: Regular evaluations contribute to the demonstration of student attainment of discipline learning outcomes.

Skills: Identify core journalism skills for demonstration and application. This would include writing, story telling, digital broadcast competencies across all platforms, publishable content, producing to deadline and reflective analysis.

\section{Models of capstone units}

A total of three models of journalism capstone units are currently used by Australian universities:

- an industry placement

- a newsroom simulation or other in-house authentic learning experience such as publishing in a web-based paper/journal

- a journalism project

Each member of the validation discussion group was familiar with the three models and readily identified the strengths and weaknesses of each. The group considered the industry placement to be valuable, but increasingly difficult to secure, of variable quality and non-inclusive, and only one institution offered a placement to all students in their final year. The newsroom simulation offered an authentic learning experience and an opportunity to demonstrate strengths. At the same time, it was resource intensive. 
The journalism project was seen to offer scope for platform neutral and across-platform journalism practice and the opportunity to engage in extended research and analysis. Also, it was seen as a means by which students could demonstrate course learning outcomes, knowledge, skills and abilities. In summary, the group believed each of the models had value and should be retained, perhaps as Capstone 1 and Capstone 2. There was general agreement that a project unit should be supported by rigorous intended learning outcomes which, while not overly restricting student choice of topic, should ensure that unit outcomes were comparable for all students.

\section{Demonstrate and apply a range of skills from the following:}

This list of skills from the 30 journalism academics was seen by the validation group as comprehensive, but they believed that students would not have to demonstrate every skill with writing, research and analysis as being core skills (Table 2). It was suggested that any skills list should make it clear that the essential journalism skills must be platform neutral.

Additional suggestions for skills to be added to the list were:

- Audio (to replace the medium specific radio)

- Advanced media literacy skills

- Knowledge of the contemporary and emerging media landscape.

Unresolved was whether a capstone unit, or indeed any other unit in the course should necessarily include skills development related to future employment options, for example, freelance operations, start-up enterprises, contract negotiation, or fee setting. Given concerns about a crowded curriculum and the varying policy requirements of the different universities, this matter is probably best left to individual universities to decide. The list of agreed skills are contained in Table 2. This list will be presented to the Journalism Education and Research Association of Australia (JERAA) for acceptance and then circulated to all universities in Australia that teach journalism.

\section{Conclusion}

Initial findings from face-to-face interviews with more than 30 journalism educators at 16 universities in Australia on the use of journalism capstone units, showed that while they are in use in more than half of Australian universities that teach journalism, there was a lack of agreed principles, standards and best practice to guide journalism educators in the design (or redesign) and implementation of final-year journalism capstone units, especially in regard to the demonstration and measurement of required graduate capabilities. Previous attempts to measure journalism graduate capabilities were linked mainly to professional industry placements with an emphasis on acquiring rather than demonstrating capabilities. In fact, there has never been a specific national strategy for the 


\section{Table 2: Summary of skills}

1. Disciplinary skills

- Story telling skills

- Writing/grammar skills

- Ability to produce a deadline

- Create content of a professional publishable standard

- Generate story ideas

- Ability to pitch ideas

- Edit

- Verification skills

- Extensive social media presence/branding

2. Skills across all platforms

- Audio

- Video

- Photography

- Broadcast in various formats

- Ability to publish across platforms

3. Professional skills

- Ethical practitioner

- Seek truth, accuracy — balance and fairness

- Mindful practitioner-reflects on consequences

- Knowledge and understanding of media law

- Media literacy skills

- Self development skills

- Resourcefulness and resilience

4. Personal skills

- Good oral and communication skills

- Interpersonal skills

- Team player

\section{Entrepreneural skills}

- Build and sustain audiences across platforms

\section{Research and analytical skills}

- How to learn, think and problem solve

promotion of measuring the capabilities of graduate journalism students in the Australian university system.

To avoid extending the research process with more data collection and discussions, I selected journalism academics who representated the diverse range of the journalism academics in Australia, and asked them to validate the data collected from the 16 universities and agree on a set of principles, skills and methods for journalism capstone units in Australian universities. These will be presented to JERAA for acceptance and then circulated to all universities in Australia that teach 
journalism. Stage three of the study will develop resources to support journalism educators in the design or redesign of capstone units. Ultimately, the findings from this 18-month study and the agreement on principles, methods and standards will provide strong evidence that journalism programmes in Australia are in line with the government's AQF level 7 standards for Bachelor degrees. Graduates will be enabled to demonstrate evidence to both educators and employers that they have acquired agreed skills and competencies for employment in a whole range of digital media and communications industries.

\section{References}

Australian Qualification Framework. (2013). AQF levels. Retrieved August 28, 2016, from www.aqf.edu.au/aqf/in-detail/aqf-levels/

Billett, S. (2011). Curriculum and pedagogic bases for effectively integrating practicebased experiences. Final Report. Sydney: Department of Education.

Cullen, T. (2014). News editors evaluate journalism courses and graduate employability. Asia Pacific Media Educator, 24(2), 1-16.

Hauhart, R., \& Grahe, J. (2015). Designing and teaching undergraduate capstone courses. San Francisco: Jossey-Bass.

Lee, N. (2015). Capstone curriculum. Retrieved January 26, 2016, from www.capstonecurriculum.com.au/one- capstone-two-capstone-bricolage/

McNamara, J., Kift, S., Bulter, D., Field, R., Brown, C., \& Gamble. N. Y. (2012). Workintegrated learning as a component of the capstone experience in undergraduate law. Asia-Pacific Journal of Cooperative Education, 13(1), 1-12.

St Clair, J. (2015). Doing it for real: Designing experiential journalism curricula that prepare students for the new and uncertain world of journalism work, Coolabah, $16(1), 122-142$.

Tanner, S., Green, K., Cullen, T.,\& O’Donnell, M. (2014). Journalism curriculum renewal: Balancing tertiary expectations and industry needs in a technological environment. Retrieved April 14, 2015, from www.olt.gov.au/project-graduate-qualities-andjournalism-curriculum-renewal balancing-tertiary-

Dr Trevor Cullen is associate professor of journalism and director of the CREATEC Research Centre at Edith Cowan University, Perth, Western Australia. $\mathrm{He}$ is also a member of the Pacific Journalism Review editorial board and a regular contributor. This research was assisted by an Australian learning and Teaching Fellowship (ALTF). An earlier version of the article was presented as a paper at the World Journalism Education Congress (WJEC) conference at Auckland University of Technology on 16 July 2016. t.cullen@ecu.edu.au 